\section{Patient-to-patient transmission of natalizumab-associated PML?}

Date received: 24 February 2017; accepted: 26

February 2017

We are intrigued by the recent case report of two stepsisters who were treated with natalizumab for multiple sclerosis (MS) and developed progressive multifocal leukoencephalopathy (PML) 5 months apart. ${ }^{1}$ This is reminiscent of our own report about the co-occurrence of PML in two MS patients who were members of a "natalizumab-infusion group". ${ }^{2}$

The two stepsisters described by Bacchetta et al. ${ }^{1}$ had close contact before and after the first patient developed PML. After PML was diagnosed in the first patient, her stepsister insisted that her neurologist ordered a magnetic resonance imaging (MRI) scan to reassure she had not PML. MRI showed a highly suggestive clinically asymptomatic lesion in her cerebellum, and PML was confirmed by CSF John Cunningham polyomavirus-polymerase chain reaction in the cerebrospinal fluid (JCV-PCR). After natalizumab was discontinued, she developed symptomatic immune reconstitution inflammatory syndrome (IRIS). ${ }^{1}$

In striking parallel, after PML was diagnosed in the first patient of our "infusion group," the second patient stopped natalizumab because of fear of PML. Six weeks later, she developed new brainstem symptoms caused by a PML lesion in her brainstem. ${ }^{2}$ PML was confirmed by CSF JCV-PCR. Subsequently, the other members of the infusion group, who met monthly to receive natalizumab infusions in the same room at their neurologist's infusion center, also discontinued natalizumab because they were concerned about infection. ${ }^{2}$

In our PML cases, we had the chance to compare the mutated non-coding control regions (NCCR) of viral DNA. We found that the JCV NCCR was unique to each patient. This seemed to argue against the possibility of direct viral transmission between the patients. However, as we discussed in our paper, "there remains the remote possibility that an archetype-like strain of JCV spread by de novo infection from one patient to the other at an earlier time point and subsequently mutated independently in the two patients." ${ }^{2}$ Alternatively, a shared pathogenic viral variant might have escaped detection by PCR.
In contrast to our report, no viral PCR sequences are available from the PML-affected stepsisters. ${ }^{1}$ The authors point out that between 2005 and 2016 there were only three cases of natalizumab-associated PML (including the two stepsisters) in a region of Switzerland encompassing 1.5 million inhabitants. A puzzling aspect of the Swiss report is that if PML indeed spread from patient to patient, there was apparently only a short latency of a few months before the second stepsister developed PML. ${ }^{1}$

Viewed together, these observations ${ }^{1,2}$ renew concern that in rare instances, transmission of natalizumabassociated PML might occur between immunocompromised patients who have close contact, as was the case with the Swiss stepsisters and with our "natalizumab infusion group." Against this background, the advice that "pre-disposed patients (e.g. natalizumabtreated patients, AIDS/immunosuppressed patients) should avoid direct contact with active PML patients"1 makes a lot of sense.

\section{Declaration of Conflicting Interests}

The author(s) declared the following potential conflicts of interest with respect to the research, authorship, and/or publication of this article: R.H. has received grant support from Bayer, Biogen, Genzyme-Sanofi, Merck-Serono, Novartis, and Teva and personal fees from Actelion, Bayer, Biogen, Genzyme-Sanofi, Medday, Merck-Serono, Novartis, Roche, and Teva. J.H. has received consultancy fees from Novartis, Genzyme, and Biogen. He has received reimbursements of congress attendance and travel costs from Novartis, Bayer, Genzyme, Biogen and Merck. T.K. has received travel expenses and personal compensations from Bayer Healthcare, Teva Pharma, Merck-Serono, Novartis, GenzymeSanofi, Roche Pharma, and Biogen, as well as grant support from Bayer-Schering AG, Novartis, and Chugai Pharma.

\section{Funding}

The author(s) received no financial support for the research, authorship, and/or publication of this article.

\section{References}

1. Bacchetta F, Mathias A, Schluep M, et al. Progressive multifocal leukoencephalopathy in two natalizumabtreated stepsisters: An intriguing coincidence. Mult Scler 2017; 23(2): 300-303.

2. Havla J, Berthele A, Kumpfel T, et al. Co-occurrence of two cases of progressive multifocal
Multiple Sclerosis Journal 2017, Vol. 23(11) 1564-1565 DOI: 10.1177 1352458517701316

(C) The Author(s), 2017. Reprints and permissions: http://www.sagepub.co.uk/ journalsPermissions.nav 
leukoencephalopathy in a natalizumab "infusion group." Mult Scler 2013; 19(9): 1213-1215.

\section{Reinhard Hohlfeld, Joachim Havla and Tania Kümpfel}

Institute of Clinical Neuroimmunology, Biomedical Center and University Hospital, Ludwig Maximilians University, Munich, Germany; Munich Cluster for Systems
Neurology (SyNergy), Ludwig Maximilians

University, Munich, Germany

Correspondence to:

\section{$R$ Hohlfeld}

Institute of Clinical Neuroimmunology, Biomedical Center and University Hospital, Ludwig Maximilians University, Klinikum der LMU München, Campus Grosshadern, Marchioninistr. 15, D-81377 München, Germany.

reinhard.hohlfeld@med.uni-muenchen.de
Visit SAGE journals online journals.sagepub.com

home/msj

@ SAGE journals 